\title{
Images of Dutchness: Popular Visual Culture, Early Cinema and the Emergence of a National Cliché, 1800-1914
}

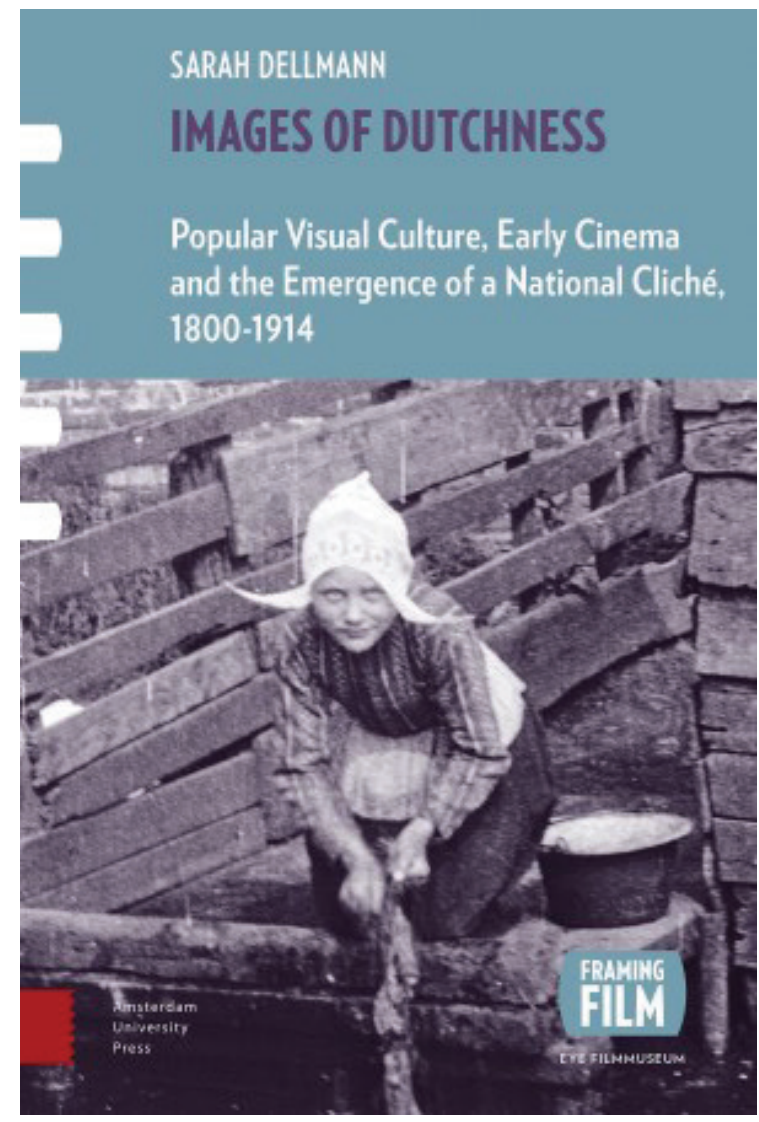

\section{Sarah Dellmann}

Images of Dutchness: Popular Visual Culture, Early Cinema and the Emergence of a National Cliché, 1800-1914

Amsterdam University Press, 2019 (Framing Film series), 424 pp., € 39.95, ISBN 9789462983007.

A coloured woodblock print by the Japanese artist Utagawa Toyoharu is the first image that Sarah Dellmann introduces in her book Images of Dutchness. This almost unrecognisable picture of a Dutch landscape was considered as a 'realistic' or 'authentic' representation of the
Netherlands in Japan. One could ask why this seemingly 'unrealistic' image for a western audience was considered as truthful for Japanese people. Yet, Dellmann interestingly poses the same question about images of the Dutch and the Netherlands in a Western context. Her book investigates knowledge production of Dutchness through images (such as engravings, film, postcards and magic lantern slides) between I800 and I9I4. Instead of if or when these images were considered 'authentic' or 'typical', Dellmann asks which and how certain parameters (word, image, viewers or readers) could prescribe an image as truthful.

Images of Dutchness is the published result of Dellmann's PhD dissertation, which she defended in 2015 at Utrecht University. The seven chapters of the book are neatly organised. Each chapter is richly illustrated with colourful reproductions of the broad variety of visual material. Dellmann let these images dictate her writing, rather than the other way around. In that way she shows the interplay between image and word in content and in form. This makes her case studies pleasant to read. The structure of the entire book contributes to the clarity of her argumentation, even if this predictability sometimes slightly reduces the reading pleasure. The first three chapters amplify on the methods and approaches - intermediality and performativity of visual material - to study the semiotic process of national clichés (chapter I); the contribution of every specific 
medium, like illustrated magazines, picture postcards, lantern slide sets and so on, to the production of knowledge of Dutchness or the Netherlands (chapter 2); and the context that lead to the development and establishment of national clichés (chapter 3). These chapters also introduce important concepts like stereotypes, supposed common knowledge, the national, Otherness, mediality and clichés, that are discussed in the following chapters.

The chapters on geography (chapter 4), anthropology (chapter 5) and tourism and consumer culture (chapter 6) are the centre of the book. They each look at three different discourses that generate knowledge on the Dutch and the Netherlands and present this knowledge as 'real'. These chapters demonstrate why and how each discourse gave different or similar meanings to typical, authentic and cliché images of the Dutch. Through this comparative strategy, Dellmann makes her central argument: that the making of meaning or knowledge production of what is considered 'Dutch' differs according the performative context wherein the image is shown. A similar image in tourist culture could for instance provoke a different meaning in an anthropological context. When a cliché would be considered 'authentic' in tourist culture, anthropologists were wary of its generalising function. Or while a concept such as 'the picturesque' remained rather abstract in tourist culture - in order not to define the experience of the tourist beforehand and in that way avoiding disappointment -, authors of narrated travel writings filled in their own experience in these concepts. They therefore described 'the picturesque' in very concrete terms. Both, however, influenced the general application and knowledge on what tourists would understand as Dutchness.
Dellmann does not only point at the performativity of meaning, clichés, stereotypes or 'supposed common knowledge' through time and space, but also through medium. She accurately shows how the new medium film relied on imageries and visual narratives of other 'earlier' media. Film, for example, relied on clichés that were already established in magic lantern lectures. Dellmann thus argues that production of meaning cannot be investigated without looking at these other media as well. Dellmann's media-archaeological approach thus interconnects these two media, blurring the lines between them. Opposed to a pre-cinematic approach, she makes past continuities visible in the present and future media. She demonstrates how in geographical discourse on the Netherlands modern elements were often not referred to as Dutch, in contrast to the rural. As a consequence of the absence of the modern in images of Dutchness, some critics resisted such a depiction of the Netherlands, as it not quite helped its economic and international reputation.

One of the main contributions of Dellmann's work is that she lays bare these cultural dynamics of clichés and the origins of the national clichés in the West. Dellmann shows how these images of Dutchness became fixed around I880 when they were increasingly produced (and re-produced) for an international market. Until the mid-nineteenth century, the repertoire of what was illustrated as Dutch was thus more extensive. Once established, these clichés became 'typically Dutch' in such a way that later on, around I890, they did not need to be explained or contextualised as 'Dutch', such as clichés like the Volendam and the Marken Fisherman.

Through nonfiction and often neglected images, such as those of private collections, 
internet web shops such as eBay or non-digitised library collections, Dellmann shows how knowledge(s) on clichés of 'Dutchness' were performed, but also how they persisted through time. However, Dellmann puts this as a conscious choice; her work makes curious to see how these clichés are interconnected to fictional images. Future research could point out the exchange and influence of both in the construction of national clichés. Dellmann's publication not only contributes to an understanding of the origins and performativity of clichés and stereotypes in the past, but also poses important questions towards the future. Dellmann encourages us to re-think the origins and strategies of Othering. She rightly admits that the Other in her research is not subjected to a cultural hierarchy, as they were not presented as lacking 'civilisation'. Nevertheless, Dellmann's intersectional approach demonstrates how Othering is not only connected to colour, but is also mediated and influenced through clichés that differ in different domains, media and cultural contexts. This helps to understand the performativity of Othering through visual narratives. Furthermore, due to her focus on the intermedial factors in meaning making, she stresses the interrelation in media between image and word, but also between media. In a lot of archives, these connections are still invisible in the organisation and disclosure of their archival material. The daring research on meaning production through different media present in her book will certainly has to be taken into account when thinking about future digitalisation of archive collections.

Marte Van Hassel, Université Libre de Bruxelles 